Miklós Vető

Von Kant zu Schelling 



\section{Miklós Vető}

\section{Von Kant zu Schelling}

Die beiden Wege des Deutschen Idealismus

Aus dem Französischen übersetzt von Hans-Dieter Gondek 
Die Open Access-Stellung dieser Publikation wurde unterstützt durch das Landesdigitalisierungsprogramm für Wissenschaft und Kultur des Freistaates Sachsen

(vgl. https://sachsen.digital/das-programm/).

Übersetzung von Miklós Vető, De Kant à Schelling, 2 Bde., 1998-2000, Editions Jérôme Millon, Grenoble, http://www.millon.com.

ISBN 978-3-11-019477-7

e-ISBN (PDF) 978-3-11-021694-3

\section{(cc) BY-NC-ND}

Dieses Werk ist lizenziert unter der Creative Commons Attribution-NonCommercial-NoDerivatives 4.0 International Lizenz. Weitere Informationen finden Sie unter http://creativecommons.org/licenses/by-nc-nd/4.0/.

\section{Library of Congress Cataloging-in-Publication Data}

Names: Veto, Miklos, 1936- author.

Title: Von Kant zu Schelling : Die beiden Wege des Deutschen Idealismus /

Miklos Veto.

Description: 1 [edition]. | Boston : De Gruyter, 2018. | Includes

bibliographical references and index.

Identifiers: LCCN 2018023447 (print) | LCCN 2018037818 (ebook) | ISBN

9783110216943 (electronic Portable Document Format (pdf) | ISBN

9783110194777 (print : alk. paper) |ISBN 9783110216943 (e-book pdf)

Subjects: LCSH: Idealism, German. | Philosophy, German--18th century. |

Philosophy, German--19th century.

Classification: LCC B2745 (ebook) | LCC B2745 .V424 2018 (print) | DDC

193--dc23

LC record available at https://lccn.loc.gov/2018023447

\section{Bibliografische Information der Deutschen Nationalbibliothek}

Die Deutsche Nationalbibliothek verzeichnet diese Publikation in der Deutschen

Nationalbibliografie; detaillierte bibliografische Daten sind im Internet über

http://dnb.dnb.de abrufbar.

(C) 2019 Miklós Vető, publiziert von Walter de Gruyter GmbH, Berlin/Boston

Dieses Buch ist als Open-Access-Publikation verfügbar über www.degruyter.com.

Druck und Bindung: $\mathrm{CPI}$ books $\mathrm{GmbH}$, Leck

@ Gedruckt auf säurefreiem Papier

Printed in Germany

www.degruyter.com 